\title{
Spiroplasma diminutum sp. nov., from Culex annulus Mosquitoes Collected in Taiwan
}

\author{
DAVID L. WILLIAMSON, ${ }^{1}$ JOSEPH G. TULLY, ${ }^{2}$ LEON ROSEN,${ }^{3}$ DAVID L. ROSE ${ }^{2}$ \\ ROBERT F. WHITCOMB,${ }^{4}$ MARIE-LOUISE ABALAIN-COLLOC, 5 \\ PATRICIA CARLE, ${ }^{6}$ JOSEPH M. BOVÉ, ${ }^{6}$ \\ AND JANETTE SMYTH ${ }^{1}$
}

\author{
Department of Anatomical Sciences, Health Sciences Center, State University of New York, Stony Brook, New York \\ 11794-8081'; Mycoplasma Section, Laboratory of Molecular Microbiology, Frederick Cancer Research Facility, \\ National Institute of Allergy and Infectious Diseases, Frederick, Maryland $21702^{2}$; Pacific Biomedical \\ Research Center, University of Hawaii at Manoa, Honolulu, Hawaii $96822^{3}$; Insect Pathology \\ Laboratory, Plant Protection Institute, Beltsville Agricultural Research Center, U.S. Department of \\ Agriculture, Beltsville, Maryland 20705 ; and Laboratoire de Bactériologie, \\ Faculté de Médécine de Brest, 29285 Brest, ${ }^{5}$ and Laboratoire de \\ Biologie Cellulaire et Moléculaire, Institut National de la \\ Recherche Agronomique and Université de Bordeaux \\ II, 33883 Villenave d'Ornon, ${ }^{6}$ France
}

\begin{abstract}
Initially, strain CUAS-1 ${ }^{\mathrm{T}}$ ( $\mathrm{T}=$ type strain), which was isolated from a frozen triturate of Culex annulus mosquitoes collected in Taiwan, was thought to be a member of spiroplasma group VII. This placement was based on the spiroplasma deformation test titer observed when strain CUAS-1 ${ }^{\text {T }}$ spiroplasmas were tested with Spiroplasma monobiae MQ-1 ${ }^{\mathrm{T}}$ antiserum. The results of subsequent reciprocal spiroplasma deformation, metabolism inhibition, and growth inhibition tests clearly revealed that strain CUAS-1 ${ }^{\mathrm{T}}$ is not serologically related to previously described spiroplasma groups (groups I to XXIV) and thus is a representative of a new group, group XXV. Strain CUAS-1 ${ }^{\mathrm{T}}$ was characterized by using the minimal standards for mollicute species descriptions. During logarithmic-phase growth, strain CUAS-1 ${ }^{\mathrm{T}}$ cells are characteristically very short helices with 1.5 to 2 helical turns ( 1 to $2 \mu \mathrm{m}$ ), highly motile, and bounded by a single trilaminar membrane and form granular colonies with satellites when the organism is grown aerobically on MID medium containing $1.6 \%$ agar. Growth in M1D broth occurs at temperatures ranging from 10 to $37^{\circ} \mathrm{C}$, and the optimum temperature is $30^{\circ} \mathrm{C}$. Substrate utilization tests revealed that cholesterol is required for growth, that glucose is hydrolyzed, and that arginine is not hydrolyzed both in the presence and in the absence of glucose. The genome of strain CUAS-1 ${ }^{T}$ is $1,080 \mathrm{kbp}$ long, and the guanine-plus-cytosine content is $26 \pm 1 \mathrm{~mol} \%$. On the basis of the results of our studies we propose that strain CUAS-1 ${ }^{\mathrm{T}}$ (group XXV) should be placed in a new species, Spiroplasma diminutum. Strain CUAS-1 (= ATCC 49235) is the type strain of $S$. diminutum.
\end{abstract}

The first mosquito spiroplasma was isolated from a triturate of female salt marsh mosquitoes (Aedes sollicitans) (12). This organism was subsequently characterized and named Spiroplasma culicicola (8). Mosquitoes have proved to be a rich source of spiroplasmas, and the following two additional mosquito-derived spiroplasmas have been characterized: Spiroplasma sabaudiense (1) and Spiroplasma taiwanense (2). In addition, several spiroplasma strains isolated from mosquitoes collected in France and the United States have recently been shown to be related to each other and to be members of three subgroups of group XVI (3). A previously existing collection of frozen mosquito triturates originally collected by one of us (L.R.) for a mosquito-borne virus survey in Southeast Asia (People's Republic of China, Japan, Taiwan) has been found to contain, in addition to $S$. taiwanense, several spiroplasma strains that cannot be placed in previously described species. One of these triturates (triturate 250657) was derived from 83 Culex annulus adult female mosquitoes collected in Taishan, Taiwan, in 1980. The spiroplasmas found in this triturate (designated strain CUAS- $1^{\mathrm{T}}$ [ $\mathrm{T}=$ type strain]) were studied because of their small size and rapid growth in broth medium,

* Corresponding author. Phone: (516) 444-3118. Fax: (516) 4443947. Electronic mail address: DWMSON@EPO.SOM.SUNYSB. EDU. traits shared with the mosquito-derived organism Spiroplasma culicicola AES-1 ${ }^{\mathrm{T}}$. The results of initial one-way serological studies in which triply cloned strain CUAS- $1^{\mathbf{T}}$ was tested with antisera to members of the 23 previously recognized spiroplasma groups and subgroups suggested that strain CUAS- $1^{\mathrm{T}}$ is serologically related to group VII (Spiroplasma monobiae) (23). However, a subsequent reciprocal serological analysis revealed that the one-way cross-reactions observed initially did not indicate that strain CUAS $-1^{\mathrm{T}}$ and the group VII spiroplasmas are related. Furthermore, the genome sizes of these two spiroplasmas are significantly different $(940 \mathrm{kbp}$ for $S$. monobiae MQ- ${ }^{\mathrm{T}}$ and 1,080 $\mathrm{kbp}$ for strain CUAS-1 $\left.{ }^{\mathrm{T}}\right)(5)$, and the $\mathrm{G}+\mathrm{C}$ contents are also significantly different $(28 \pm 1 \mathrm{~mol} \%$ for strain MQ- ${ }^{\mathrm{T}}$ and $26 \pm 1 \mathrm{~mol} \%$ for strain CUAS- $\left.{ }^{\mathrm{T}}\right)$.

In this paper we present data obtained in a taxonomic study of strain CUAS- $1^{\mathrm{T}}$ and propose that this strain should be given species status as the type strain of Spiroplasma group XXV.

\section{MATERIALS AND METHODS}

Origins of strains. Strain CUAS-1 ${ }^{\mathrm{T}}$ was isolated by one of us (L.R.) from a frozen triturate of 83 adult female $C$. annulus mosquitoes collected on 5 September 1980, in Taishan, Taiwan. In 1986, this triturate was thawed and inoculated into SP-4 broth. When the culture was found to consist of helical filaments, a 10-fold dilution series in SP-4 medium was shipped to the State University of New York at Stony Brook for cloning and serological studies; this culture was designated spiroplasma Sp18. At the fifth passage following isolation, spiro- 
TABLE 1. Sterol requirement of strain CUAS- $1^{\mathrm{T}}$

\begin{tabular}{lccccccc}
\hline \multirow{2}{*}{ Sterol(s) } & \multicolumn{6}{c}{$\begin{array}{c}\text { Titer of spiroplasmas (CCU/ml) after } \\
\text { incubation at 30 } 30^{\circ} \mathrm{C} \text { on: }\end{array}$} \\
\cline { 2 - 8 } & Day 1 & Day 2 & Day 3 & Day 4 & Day 5 & Day 6 \\
\hline None & $\mathrm{N}^{a}$ & $\mathrm{~N}$ & $\mathrm{~N}$ & $\mathrm{~N}$ & $\mathrm{~N}$ & $\mathrm{~N}$ \\
Albumin $(0.5 \%)+$ palmitic & $\mathrm{N}$ & $\mathrm{N}$ & $\mathrm{N}$ & $\mathrm{N}$ & $\mathrm{N}$ & $\mathrm{N}$ \\
$\quad$ acid $(10 \mu \mathrm{g} / \mathrm{ml})$ & & & & & & \\
Albumin $(0.5 \%)+$ palmitic & $\mathrm{N}$ & $\mathrm{N}$ & $\mathrm{N}$ & $\mathrm{N}$ & $\mathrm{N}$ & $\mathrm{N}$ \\
$\quad$ acid $(10 \mu \mathrm{g} / \mathrm{ml})+$ Tween & & & & & & \\
$\quad 80(0.01 \%)$ & & & & & & \\
Cholesterol $(1 \mu \mathrm{g} / \mathrm{ml})$ & $10^{3}$ & $10^{6}$ & $10^{7}$ & $10^{7}$ & $10^{7}$ & \\
Cholesterol $(5 \mu \mathrm{g} / \mathrm{ml})$ & $10^{4}$ & $10^{7}$ & $10^{9}$ & $10^{9}$ & $10^{9}$ & \\
Cholesterol $(10 \mu \mathrm{g} / \mathrm{ml})$ & $10^{5}$ & $10^{7}$ & $10^{8}$ & $10^{8}$ & $10^{8}$ & \\
Cholesterol $(20 \mu \mathrm{g} / \mathrm{ml})$ & $10^{5}$ & $10^{7}$ & $10^{8}$ & $10^{8}$ & $10^{8}$ & \\
Bovine serum fraction $(1 \%)$ & $10^{4}$ & $10^{7}$ & $10^{7}$ & $10^{7}$ & $10^{7}$ & \\
\hline
\end{tabular}

${ }^{a} \mathrm{~N}$, no growth.

plasma Sp18 was filter cloned three times by using previously described procedures (13). At the end of the third cloning, a single colony was selected and designated strain CUAS-1 ${ }^{\mathrm{T}}$. A $25-\mathrm{ml}$ batch culture was prepared, and portions of this culture were transferred to sterile microtubes for storage at $-70^{\circ} \mathrm{C}$; the remainder was transferred to ampoules for lyophilization. A second triturate (triturate 250648) from 100 female adult Culex tritaeniorhynchus mosquitoes, also collected in Taishan, Taiwan, on 5 September 1980, contained spiroplasma Sp19, which was morphologically similar to strain CUAS $-1^{\mathrm{T}}$. After filter cloning three times, this strain was designated strain CT-4, and it was subsequently shown to be serologically identical to strain CUAS- $1^{\mathrm{T}}$.

Culture media and cultivation procedures. Both MID medium and SP-4 medium (19) were used for broth cultures. Solid M1D and SP-4 media were prepared by adding Noble agar (Difco Laboratories, Detroit, Mich.) to a final concentration of 1.6 or $2.25 \%$. Broth and agar cultures were grown aerobically at either room temperature $\left(23^{\circ} \mathrm{C}\right)$ or $30^{\circ} \mathrm{C}$

Source of other spiroplasmas. Spiroplasmas obtained from frozen $\left(-70^{\circ} \mathrm{C}\right)$ batch cultures representing strains of the 23 previously recognized groups and the subgroups of groups I, VIII, and XVI and eight new strains that represented putative new groups $(15,16,20,23)$ were used in various procedures.

Filtration studies. A fresh culture of strain CUAS-1 ${ }^{\mathrm{T}}$ in M1D broth lacking penicillin was passed through a series of membrane filters with pore diameters of $450,300,220$, and $100 \mathrm{~nm}$ by using a syringe and minimum hand pressure. A 50 - $\mu$ l portion of each filtrate was then diluted (10-fold serial dilutions) in $450 \mu$ l of M1D medium lacking penicillin. One dilution series was used as a control. Al of the tubes were incubated at room temperature. After 4 days, the tubes were examined for growth by identifying the last tube in which the color had changed Cultures of strain CUAS-1 ${ }^{\mathrm{T}}$ were maintained in medium without penicillin $\mathrm{G}$ for more than five consecutive passages without reversion to bacterial forms.

Temperature requirements. Temperature requirements were determined by inoculating $900 \mu \mathrm{l}$ of M1D medium lacking penicillin with $100 \mu \mathrm{l}$ of a spiroplasma culture. Then 10 -fold dilutions were prepared in six different series, and each of these series was incubated at one of seven temperatures $(10,18,22,26$, 30,37 , and $\left.42^{\circ} \mathrm{C}\right)$. Growth was assessed by monitoring the number of colorchanging units (CCU) during a 7-day period. Each of the dilution series was examined at its endpoint by dark-field microscopy.

Sterol requirements. The growth response to cholesterol was determined by first preparing BSR (18) medium adjusted to $\mathrm{pH}$ 7.4. Seven individual flasks containing this medium without bovine serum were prepared and subsequently supplemented with albumin, palmitic acid, Tween 80 , cholesterol, and $1 \%$ Bacto PPLO Serum Fraction (Difco) (Table 1). Each of these preparations was distributed to tubes and incubated at $30^{\circ} \mathrm{C}$. Growth responses were assessed by monitoring the number of CCU per milliliter (18)

Biochemical tests. Tests to determine the utilization of glucose, arginine, and urea were performed by using previously described procedures (4). All tubes were incubated at room temperature $\left(21\right.$ to $\left.23^{\circ} \mathrm{C}\right)$. The ability to utilize a substrate was evaluated by observing the color change of the $\mathrm{pH}$ indicator (phenol red) and by dark-field examination.

Morphology. Strain CUAS-1 ${ }^{\mathrm{T}}$ cells were routinely examined by dark-field microscopy. For electron microscopy, strain CUAS- $1^{\mathrm{T}}$ cells were fixed for $3 \mathrm{~h}$ in $3 \%$ (final concentration) glutaraldehyde that was added directly to the culture, pelleted by centrifugation at $16,000 \times \mathrm{g}$, postfixed in $1 \%$ osmium tetroxide for 1 h, dehydrated in acetone, and embedded in Epon-araldite; sections were stained with $2 \%$ aqueous uranyl acetate and Reynold's lead citrate.

Serological tests. Hyperimmune serum against strain CUAS $-1^{\mathrm{T}}$ was prepared in rabbits as described previously (11). Antisera were heat inactivated at $56^{\circ} \mathrm{C}$ for $30 \mathrm{~min}$, membrane filtered (pore size, $450 \mathrm{~nm}$ ), and stored at $-20^{\circ} \mathrm{C}$. Disc growth inhibition (GI) tests in which we used undiluted CUAS-1 ${ }^{\mathrm{T}}$ antiserum and representative spiroplasma strains on SP-4 hard agar were performed as described previously (22). Reciprocal deformation (DF) and metabolism inhibition (MI) tests were performed by using previously described procedures $(24,26)$.

Genomic analysis. The genome size of strain CUAS $-1^{\mathrm{T}}$ was determined by pulsed-field gel electrophoresis as described by Carle et al. (5). The guanineplus-cytosine $(\mathrm{G}+\mathrm{C})$ content of purified DNA was determined by the buoyant density, melting temperature, and high-performance liquid chromatography methods (6). The procedures used to extract and purify strain CUAS- $1^{\mathrm{T}}$ DNA were the procedure described by Carle et al. (6). Purified DNA from Spiroplasma citri $\mathrm{R} 8 \mathrm{~A} 2$ was used as a control $(\mathrm{G}+\mathrm{C}$ content, $26 \pm 1 \mathrm{~mol} \%$; genome size, 1,820 $\mathrm{kbp})$.

\section{RESULTS AND DISCUSSION}

Cultural and morphological properties. Strain CUAS- $1^{\mathrm{T}}$ grew very rapidly and to very high titers in both M1D medium and SP-4 medium. For example, after $24 \mathrm{~h}$ the titer of a strain CUAS $-1^{\mathrm{T}}$ batch culture in M1D broth growing at room temperature $\left(21\right.$ to $23^{\circ} \mathrm{C}$ ), which was prepared by using a $0.1 \%$ inoculum from the first passage after triple cloning, was $10^{10}$ $\mathrm{CCU} / \mathrm{ml}$. During logarithmic growth strain CUAS-1 ${ }^{\mathrm{T}}$ cells were short filaments (length, 1 to $2 \mu \mathrm{m}$ ) having one to three helical turns. They were highly motile, and exhibited rapid rolling or tumbling movements that made it difficult to discern their helical morphology when samples of broth cultures were observed by dark-field microscopy. Suspending living strain CUAS $-1^{\mathrm{T}}$ cells in methylcellulose (final concentration, $0.4 \%$ ) allowed us to determine the typical cell length by dark-field microscopy (Fig. 1A). Electron microscopy of thin sections of CUAS- $1^{t}$ cells embedded in plastic revealed that they had a typical trilaminar membrane (Fig. 1B).

Strain CUAS $-1^{\mathrm{T}}$ growing aerobically on solid M1D medium containing $1.6 \%$ Noble agar formed colonies with dense centers, granular perimeters, and nondistinct edges, as well as small satellite colonies (Fig. 1C). Colony growth occurred on or just below the surface.

The numbers of CCUs per milliliter after filtration through membrane filters having average pore sizes of 450,300 , and $220 \mathrm{~nm}$ were $2 \times 10^{10}, 2 \times 10^{9}$, and $2 \times 10^{8}$, respectively. The organisms did not pass through membrane filters having an average pore size of $100 \mathrm{~nm}$.

Biochemical properties. Strain CUAS $-1^{\mathrm{T}}$ fermented glucose but did not hydrolyze arginine and urea.

Sterol requirements. Strain CUAS- $1^{\mathrm{T}}$ did not grow in basal medium without serum or in basal medium supplemented with albumin, palmitic acid, and Tween 80 (Table 1). However, addition of $1 \%$ serum fraction to the basal medium or addition of 1 to $20 \mu \mathrm{g}$ of cholesterol per $\mathrm{ml}$ to the basal medium containing fatty acid supplements significantly stimulated growth. In a study in which mollicutes were tested for growth responses to Tween 80, Rose et al. (10) showed that strain CUAS $-1^{\mathrm{T}}$ grew only when the medium contained sterol (serum).

Serological tests. A list containing the strains used in the serological studies and the results of some homologous GI, DF, and MI tests have been published previously (16). In addition, the MI titers of group II strain DW-1, group XX strain LD-1, and ungrouped strain TIUS-1 were 39,000, 117,000 , and 39,000 , respectively, and strain TIUS-1 produced a 9-mm inhibition zone in the GI test. The results of homologous serological tests performed with CUAS $-1^{\mathbf{T}}$ were as follows: size of GI zone, $5 \mathrm{~mm}$; DF titer, 5,120; and MI titer, 13,000 . In GI tests performed with strain CUAS- $1^{\mathrm{T}}$ and heterologous antisera produced against representative strains, none of the antisera inhibited the growth of strain CUAS $-1^{\mathrm{T}}$. Likewise, in reciprocal GI tests, strain CUAS- $1^{\mathrm{T}}$ antiserum did not inhibit the growth of any of the spiroplasma strains that were representatives of previously described or putative groups or subgroups. 

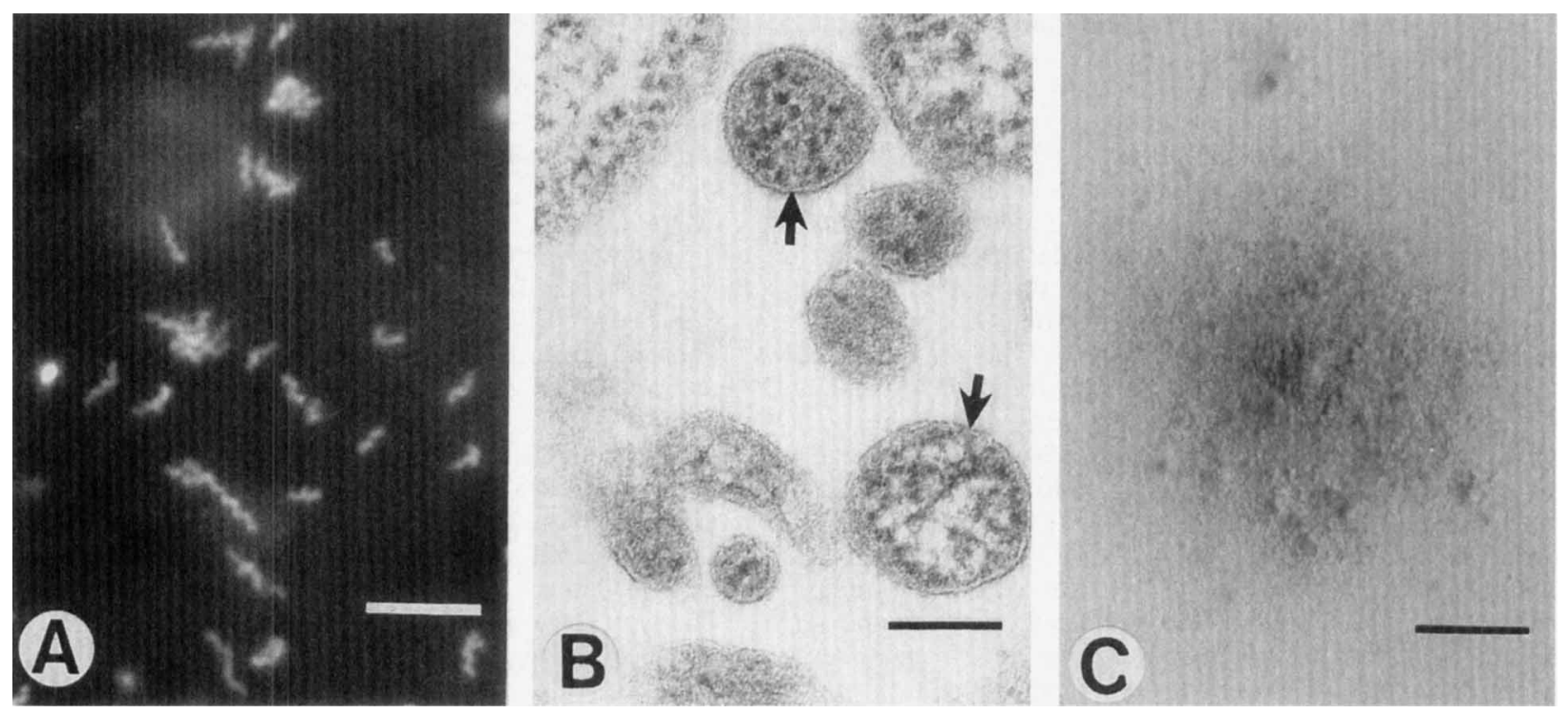

FIG. 1. Strain CUAS-1 $1^{\mathrm{T}}$. (A) Morphology of living strain CUAS-1 ${ }^{\mathrm{T}}$ cells (1 volume of culture suspended in 2 volumes of M1D medium containing $1.6 \%$ methylcellulose). Dark-field flash photograph showing typical short strain CUAS-1 ${ }^{\mathrm{T}}$ filaments. Bar $=5 \mu \mathrm{m}$. (B) Electron micrograph of a thin section of a strain CUAS $-1^{\mathrm{T}}$ cell pellet. The arrows indicate the single trilaminar plasma membrane. Bar $=100 \mathrm{~nm}$. (C) Colony morphology of strain CUAS-1 ${ }^{\mathrm{T}}$ grown for 6 days on M1D medium containing $1.6 \%$ Noble agar at $30^{\circ} \mathrm{C}$ under aerobic conditions. Bar $=100 \mu \mathrm{m}$.

Table 2 shows the reactions of the spiroplasma strains that produced positive cross-reactions in DF and/or MI tests with strain CUAS-1 $1^{\mathrm{T}}$ and its specific antiserum. As shown in Table 2, when reciprocal DF tests were performed, we observed cross-reactions between strain CUAS-1 ${ }^{\mathbf{T}}$ and the group III organisms Spiroplasma floricola BNR1 and OBMG, but not between strain CUAS- $1^{\mathrm{T}}$ and strain $23-6^{\mathrm{T}}$. The DF test titers when strains OBMG and BNR1 were used as antigens with CUAS $-1^{\mathrm{T}}$ antiserum were 640 , but the DF test titer was $<20$ when $23-6^{\mathrm{T}}$ was used as the antigen. The DF test titers in the reciprocal tests, when strain CUAS- $1^{\mathrm{T}}$ antigen was used with the antisera of the three strains, were $<20$. Similar crossreactions were observed with the group VII organism $S$. monobiae MQ- $1^{\mathrm{T}}$. When MQ-1 ${ }^{\mathrm{T}}$ was used as the antigen with
CUAS $-1^{\mathrm{T}}$ antiserum, the DF test titer was 40 , and in the reciprocal test the titer was 320 . With the subgroup organism XVI-1 Spiroplasma cantharicola $\mathrm{CC}-1^{\mathrm{T}}$, the reciprocal MI test titer was 54 , compared with homologous titers of 39,000 for strain $\mathrm{CC}-1^{\mathrm{T}}$ and 13,000 for strain CUAS- $1^{\mathrm{T}}$. Although reciprocal tests were performed, cross-reactions were observed in only one of the three serological tests. The titers of the crossreactions were always much lower than the homologous titers and usually higher when CUAS- $1^{\mathrm{T}}$ antigen and heterologous antiserum were used. They were also erratic in that repeat tests produced different titers.

We also observed some one-way cross-reactions; for example, in the MI test performed with the group XI organism Spiroplasma velocicrescens $\mathrm{MQ}-4^{\mathrm{T}}$ as the antigen and strain

TABLE 2. Serological reactions of spiroplasma strains that exhibited positive cross-reactions in DF and MI tests performed with strain CUAS- $1^{\mathrm{T}}$ and its specific antiserum ${ }^{a}$

\begin{tabular}{|c|c|c|c|c|c|c|c|}
\hline \multirow{3}{*}{ Group } & \multirow{3}{*}{ Strain } & \multirow{2}{*}{\multicolumn{2}{|c|}{ Homologous reactions }} & \multicolumn{4}{|c|}{ Heterologous reactions } \\
\hline & & & & \multicolumn{2}{|c|}{ DF titer } & \multicolumn{2}{|c|}{ MI titer } \\
\hline & & DF titer & MI titer ${ }^{r}$ & $\mathrm{AG}$ direction ${ }^{d}$ & AS direction ${ }^{e}$ & AG direction ${ }^{d}$ & AS direction \\
\hline \multirow[t]{3}{*}{ III } & S. floricola $23-6^{\mathrm{T}}$ & 2,560 & 13,000 & $<20$ & $<20$ & $<18$ & $<18$ \\
\hline & OBMG & 5,120 & 13,000 & $<20$ & 640 & $<18$ & $<18$ \\
\hline & BNR1 & 10,240 & 39,000 & $<20$ & 640 & $<18$ & $<18$ \\
\hline VII & S. monobiae $\mathrm{MQ}-1^{\mathrm{T}}$ & 5,120 & $>117,000$ & 40 & 320 & $<18$ & $<18$ \\
\hline XVI-1 & S. cantharicola $\mathrm{CC}-1^{\mathrm{T}}$ & 1,280 & 39,000 & $<20$ & $<20$ & 54 & 54 \\
\hline XVI-2 & CB-1 & 1,280 & 39,000 & 80 & $<20$ & $<18$ & $<18$ \\
\hline XVI-3 & Ar- -1357 & 1,280 & $>117,000$ & 320 & $<20$ & $<18$ & $<18$ \\
\hline Ungrouped & PLHS-1 (scorpionfly) & 2,560 & 117,000 & $<20$ & $<20$ & 54 & $<18$ \\
\hline Ungrouped & PALS-1 (dragonfiy) & 1,280 & 4,374 & $<20$ & $<20$ & 18 & $<18$ \\
\hline
\end{tabular}

${ }^{a}$ We performed reciprocal tests with strain CUAS-1 ${ }^{\mathrm{T}}$ and sera and antigens of members of the 23 previously described groups, including all 11 subgroups that have been described, as well as eight strains representing ungrouped spiroplasma clusters.

${ }^{b}$ Reciprocal of the highest antiserum dilution that deformed one-half the spiroplasmas in either homologous or heterologous tests. The homologous DF titer of strain CUAS-1 ${ }^{\mathrm{r}}$ was 5,120 .

${ }^{c}$ Reciprocal of the highest antiserum dilution that resulted in MI in either homologous or heterologous tests. The homologous MI titer of strain CUAS-1 ${ }^{\mathrm{T}}$ was 13,000 .

${ }^{d}$ Test in which we used the spiroplasma indicated as the antigen and antiserum to strain CUAS- ${ }^{\mathrm{T}}$.

Test in which we used strain CUAS-1 ${ }^{\mathrm{T}}$ as the antigen and antiserum to the strain indicated. 
CUAS- $1^{\mathrm{T}}$ antiserum, the titer was 1,458 , and in the DF test performed with CUAS $-1^{\mathrm{T}}$ antiserum and subgroup XVI-2 and XVI-3 strains CB-1 and Ar-1357, the titers were 80 and 320 , respectively. Such irregular cross-reactions are common in serological studies of spiroplasmas and may reflect some shared epitopes, but information concerning this possibility is lacking. The reciprocal tests for all other strains resulted in DF titers of $<20$ or MI titers of $<18$. Our serological data clearly demonstrate that strain CUAS $-1^{\mathrm{T}}$ is not serologically related to previously described Spiroplasma species or groups.

Genome size and DNA base composition. The genome size of the undigested linear DNA molecule of strain CUAS- $1^{\mathrm{T}}$, as determined by pulsed-field gel electrophoresis, was $1,080 \mathrm{kbp}$. Thus, the strain CUAS- $1^{\mathrm{T}}$ genome is $13 \%$ larger than the genome of $S$. monobiae strain MQ-1 ${ }^{\mathrm{T}}(940 \mathrm{kbp})$. The $\mathrm{G}+\mathrm{C}$ content of the DNA of strain CUAS $-1^{\mathrm{T}}$ was $26 \pm 1 \mathrm{~mol} \%$ compared with $28 \pm 1$ mol\% for strain $\mathrm{MQ}-1^{\mathrm{T}}$.

Habitat. Mosquitoes are an excellent source of new spiroplasma isolates. Previously described mosquito-derived spiroplasma species include $S$. culicicola (group X) (from Aedes sollicitans collected in New Jersey) (8), S. sabaudiense (group XIII) (from Aedes sticticus/vexans collected in the French Alps) (1), and S. taiwanense (group XXII) (from Culex tritaeniorhynchus collected in Taiwan) (2). In addition, subgroups XVI-2 and XVI-3 contain several strains of spiroplasmas isolated from various species of mosquitoes collected in the French Alps and in Alabama. Strain CT-4, which is morphologically identical to strain CUAS $-1^{\mathrm{T}}$ and serologically homologous and produces almost the same polyacrylamide gel electrophoresis whole-cell protein and EcoRI-HindIII restriction enzyme band patterns (data not shown), was isolated from a triturate of female $C$. tritaeniorhynchus mosquitoes collected in Taiwan on the same day as the $C$. annulus females from which CUAS-1 ${ }^{\mathrm{T}}$ was derived. Despite the apparent potential, none of the mosquito-derived spiroplasma strains is known to be pathogenic to any vertebrate or to be associated with pathogenesis in its mosquito host. Mosquitoes are known to feed on flower nectaries, and nectaries may provide the medium through which horizontal transfer of spiroplasmas occurs among mosquitoes and other flower-visiting arthropods. The ecology of mosquitoassociated spiroplasmas has been reviewed recently by Chastel and Humphery-Smith (7).

Many properties of strain CUAS-1 ${ }^{\mathrm{T}}$, including the lack of a cell wall, the failure to revert to walled forms when it is grown in the absence of an antibiotic, penicillin resistance, the ability to pass through 220-nm-pore-size filters, and formation of dense-center colonies on solid medium, are all characteristics of members of the class Mollicutes $(9,14)$. The helical morphology of CUAS- $1^{\mathbf{T}}$, its requirement for sterol or serum for growth, its optimum growth at $30^{\circ} \mathrm{C}$, and the characteristics of its genome place this strain in the order Entomoplasmatales, the family Spiroplasmataceae, and the genus Spiroplasma (14, $17,21,25)$. Our serological studies, in which three standard procedures (GI, DF, and MI tests) were used, revealed that strain CUAS $-1^{\mathrm{T}}$ is not related to representative strains of previously described groups I through XXIV or subgroups or to any of seven strains that represent new putative groups. Therefore, strain CUAS $-1^{\mathrm{T}}$ was designated the representative strain of group XXV. The name Spiroplasma diminutum is proposed for strain CUAS-1 ${ }^{T}$.

The taxonomic description below summarizes the properties of this new species.

Description of Spiroplasma diminutum sp. nov. Spiroplasma diminutum (di.min.u'tum. L. verb deminuere, to make pieces, make smaller; L. neut. partic. perf. diminutum, made smaller, reflecting a smaller size). Cells are short (1- to $2-\mu \mathrm{m})$ helical filaments (diameter 100 to $200 \mathrm{~nm}$ ) that appear to be rapidly moving irregularly spheroidal bodies when logarithmic-phase broth cultures are examined under dark-field illumination. Colonies on solid medium containing $1.6 \%$ Noble agar have dense centers, granular perimeters, and nondistinct edges with satellite colonies.

Chemoorganotroph. Acid is produced from glucose. Does not hydrolyze arginine or urea. Film and spot reaction positive. Does not hemadsorb guinea pig erythrocytes.

Cholesterol or serum is required for growth.

The temperature range for growth is 10 to $37^{\circ} \mathrm{C}$; the optimum temperature is $30^{\circ} \mathrm{C}$. Grows well in SP-4, M1A, or M1D medium.

Serologically distinct from previously described Spiroplasma species. Isolated from a frozen triturate of female $C$. annulus mosquitoes. Pathogenicity for insects has not been determined.

The $\mathrm{G}+\mathrm{C}$ content of the DNA is $26 \pm 1 \mathrm{~mol} \%$. The genome size is $1,080 \mathrm{kbp}$.

The type strain is strain CUAS-1 (= ATCC 49235).

\section{ACKNOWLEDGMENTS}

This study was supported in part by Binational Agricultural Research and Development grant US-1902-90R.

We sincerely appreciate the help of Mark Aronoff, Department of Linguistics, State University of New York at Stony Brook, in deriving the Latin name.

\section{REFERENCES}

1. Abalain-Colloc, M. L., C. Chastel, J. G. Tully, J. M. Bové, R. F. Whitcomb B. Gilot, and D. L. Williamson. 1987. Spiroplasma sabaudiense sp. nov., a new species from mosquitoes collected in France. Int. J. Syst. Bacteriol. 37:260265

2. Abalain-Colloc, M. L., L. Rosen, J. G. Tully, J. M. Bové, C. Chastel, and D. L. Williamson. 1988. Spiroplasma taiwanense sp. nov. from Culex tritaeniorhynchus mosquitoes collected in Taiwan. Int. J. Syst. Bacteriol. 38:103 107

3. Abalain-Colloc, M. L., D. L. Williamson, P. Carle, J. H. Abalain, F. Bonnet J. G. Tully, M. Konai, R. F. Whitcomb, J. M. Bové, and C. Chastel. 1993 Division of group XVI spiroplasmas into subgroups. Int. J. Syst. Bacteriol. 43:342-346.

4. Aluotto, B. B., R. G. Wittler, C. O. Williams, and J. E. Faber. 1970. Standardized bacteriologic techniques for the characterization of Mycoplasma species. Int. J. Syst. Bacteriol. 20:35-58.

5. Carle, P., F. Laigret, J. G. Tully, and J. M. Bové. 1995. Heterogeneity of genome sizes within the genus Spiroplasma. Int. J. Syst. Bacteriol. 45:178181.

6. Carle, P., C. Saillard, and J. M. Bové. 1983. DNA extraction and purification. Methods Mycoplasmol. 1:295-299.

7. Chastel, C., and I. Humphery-Smith. 1991. Mosquito spiroplasmas, p. 149 205. In K. Harris (ed.), Advances in disease vector research, vol. 7. SpringerVerlag, New York.

8. Hung, S. H., T. A. Chen, R. F. Whitcomb, J. G. Tully, and Y. X. Chen. 1987 Spiroplasma culicicola sp. nov. from the salt marsh mosquito Aedes sollicitans. Int. J. Syst. Bacteriol. 37:365-370.

9. International Committee on Systematic Bacteriology Subcommittee on the Taxonomy of Mollicutes. 1979. Proposals of minimum standards for descriptions of new species of the class Mollicutes. Int. J. Syst. Bacteriol. 29:172-180.

10. Rose, D. L., J. G. Tully, J. M. Bové, and R. F. Whitcomb. 1993. A test for measuring growth responses of mollicutes to serum and polyoxyethylene sorbitan. Int. J. Syst. Bacteriol. 43:527-532.

11. Senterfit, L. B. 1983. Preparation of antigens and antisera. Methods Mycoplasmol. 1:401-404

12. Slaff, M., and T. A. Chen. 1982. The isolation of a spiroplasma from Aedes sollicitans (Walker) in New Jersey. J. Fla. Anti-Mosq. Assoc. 53:19-21.

13. Tully, J. G. 1983. Cloning and filtration techniques for mycopiasmas. Methods Mycoplasmol. 1:173-177.

14. Tully, J. G., J. M. Bové, F. Laigret, and R. F. Whitcomb. 1993. Revised taxonomy of the class Mollicutes: proposed elevation of a monophyletic cluster of arthropod-associated mollicutes to ordinal rank (Entomoplasmatales ord. nov.), with provision for familial rank to separate species with nonhelical morphology (Entomoplasmataceae fam. nov.) from helical species (Spiroplasmataceae), and emended descriptions of the order Mycoplasmatales, family Mycoplasmataceae. Int. J. Syst. Bacteriol. 43:378-385.

15. Tully, J. G., D. L. Rose, E. Clark, P. Carle, J. M. Bové, R. B. Henegar, R. F. Whitcomb, D. E. Colflesh, and D. L. Williamson. 1987. Revised group clas- 
sification of the genus Spiroplasma (class Mollicutes), with proposed new groups XII to XXIII. Int. J. Syst. Bacteriol. 37:357-364.

16. Tully, J. G., D. L. Rose, C. E. Yunker, P. Carle, J. M. Bové, D. L. Williamson, and R. F. Whitcomb. 1995. Spiroplasma ixodetis sp. nov., a new species from Ixodes pacificus ticks collected in Oregon. Int. J. Syst. Bacteriol. 45:23-28.

17. Tully, J. G., and R. F. Whitcomb. 1991. The genus Spiroplasma, p. 1960 1980. In A. Balows, H. G. Trüper, M. Dworkin, W. Harder, and K.-H. Schleifer (ed.), The prokaryotes, 2nd ed., vol. 2. Springer-Verlag, New York.

18. Tully, J. G., R. F. Whitcomb, D. L. Rose, and J. M. Bové. 1982. Spiroplasma mirum, a new species from the rabbit tick (Haemaphysalis leporispalustris). Int. J. Syst. Bacteriol. 32:92-100.

19. Whitcomb, R. F. 1983. Culture media for spiroplasmas. Methods Mycoplasmol. 1:147-158.

20. Whitcomb, R. F., J. M. Bové, T. A. Chen, J. G. Tully, and D. L. Williamson. 1987. Proposed criteria for an interim serogroup classification for members of the genus Spiroplasma (class Mollicutes). Int. J. Syst. Bacteriol. 37:82-84.

21. Whitcomb, R. F., and J. G. Tully. 1984. Family III. Spiroplasmataceae Skripal 1983, 408. Genus I. Spiroplasma, p. 781-787. In N. R. Krieg and J. G. Holt (ed.), Bergey's manual of systematic bacteriology, vol. 1. Williams and Wilkins, Baltimore.

22. Whitcomb, R. F., J. G. Tully, P. McCawley, and D. L. Rose. 1982. Application of the growth inhibition test to Spiroplasma taxonomy. Int. J. Syst. Bacteriol. 32:387-394.

23. Whitcomb, R. F., J. G. Tully, D. L. Williamson, J. M. Bové, F. E. French, M. Konai, G. Gasparich, M. Abalain-Colloc, C. Saillard, C. Chastel, P. Carle, D. L. Rose, R. Henegar, E. A. Clark, and K. J. Hackett. 1992. Revised classification of spiroplasmas. IOM Lett. 2:134.

24. Williamson, D. L., J. G. Tully, and R. F. Whitcomb. 1979. Serological relationships of spiroplasmas as shown by combined deformation and metabolism inhibition tests. Int. J. Syst. Bacteriol. 29:345-351.

25. Williamson, D. L., J. G. Tully, and R. F. Whitcomb. 1989. The genus Spiroplasma, p. 71-111. In R. F. Whitcomb and J. G. Tully (ed.), The mycoplasmas, vol. 5. Academic Press, New York.

26. Williamson, D. L., R. F. Whitcomb, and J. G. Tully. 1978. The spiroplasma deformation test, a new serological method. Curr. Microbiol. 1:203-207. 